Vol. LXIV No 12014

\title{
CONSIDERATIONS ON THE SELECTION OF MATERIALS FOR PROSTHETIC PARTS OBTAINED BY INCREMENTAL FORMING
}

\author{
CARMEN COTIG $\breve{A}$ \\ Faculty of Engineering, Department of Industrial Machines and Equipment, "Lucian Blaga" University of \\ Sibiu, Sibiu, Romania, carmen.cotiga@ulbsibiu.ro \\ OCTAVIAN BOLOGA \\ Faculty of Engineering, Department of Industrial Machines and Equipment, "Lucian Blaga" University of \\ Sibiu, Sibiu, Romania, octavian.bologa@ulbsibiu.ro \\ CRISTIAN DEAC \\ Faculty of Engineering, Department of Industrial Machines and Equipment, "Lucian Blaga" University of \\ Sibiu, Sibiu, Romani, cristian.deac@ulbsibiu.ro
}

\begin{abstract}
Incremental forming is a novel but promising procedure for the flexible manufacturing of parts starting from metal sheets. It could be very useful in the medical area and especially in orthopedic prosthetics, where each part needs to be very precisely made, but at the same time has to have a unique shape. In this context, the selection of the material that could best satisfy the manufacturing and usage requirements is very important. The current paper suggests a unified parameter that could be used for assessing the suitability of a specific material for the manufacturing, by incremental forming, of prosthetic parts that would be used in human surgery.
\end{abstract}

Keywords: assessment parameter, prosthetic part, incremental forming

\section{Introduction}

Flexibility has become an increasingly important feature in the modern manufacturing systems, as industrial companies seek to remain competitive by catering to a wider and wider segment of customers and thus have to be able to quickly switch their production from one product to a possibly very different one in a short range of time.

The area of metal forming procedures has not remained untouched by these developments. While classical procedures like drawing, deep drawing, blanking or hydroforming have benefitted from numerous technological innovations, they still remained costly in the case of small batch and prototypes production, as they require the usage of tools that match the shape of the part that needs to be realised (Blaga, 2011). Therefore, the introduction of new procedures as alternatives to the classical ones was a clear necessity. One such new procedure, that has started to gain worldwide attention is the incremental forming of sheet metal. At this procedure, forming is carried out by a tool with a generalised shape that moves along a predetermined path to cover the future part's contour, basically carrying out a sequence of localised forming processes. Compared to classical forming procedures, this forming method has a high degree of flexibility, the same, relatively simple and cheap tool allowing the manufacturing of very diverse part configurations and sizes, even made of different materials and eliminating the time-consuming tool exchange operation for new parts. Figure 1 (Göttmann, 2011) presents, for example, two variants of carrying out the asymmetric incremental sheet forming (AISF) procedure. 


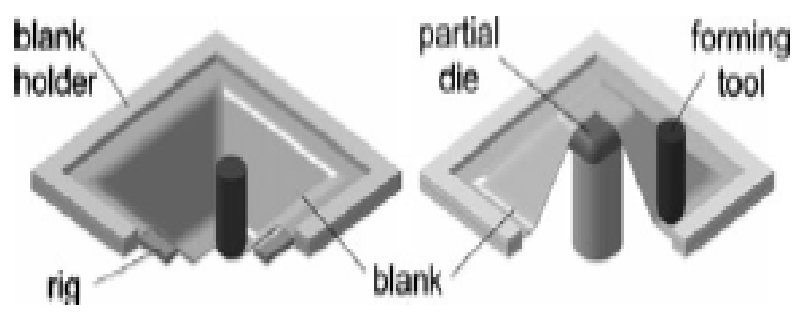

Source: Göttmann, 2011

One of the main disadvantages presented by this procedure is that the forming time is much larger than in the case of the classical procedures, so it is economically viable only for parts produced as prototypes, unique parts or in small batches.

On the other hand, it allows the achievement of much higher forming degrees than those achievable through classic forming operation, so even materials that otherwise are difficult to process by classical forming can be processed with this procedure. This makes it even more important to determine in a fast and simple method how suitable a certain material would be for processing through this method or which material would be best suited for the manufacturing of an incrementally formed part.

A promising application for this new procedure, targeted by the authors of this paper, is the manufacturing of custom-shaped prosthetic parts for use in various areas of human medicine. Such prostheses can have a functional role, when they target the replacing of a functional component of the human body, or an aesthetic role, when they target the solving of problems related to the appearance of the human body. Table 1 (Pop, 2004) presents a synopsis of the most important types of prostheses.

Types of prostheses for the human body

\begin{tabular}{|c|c|c|}
\hline \multicolumn{2}{|c|}{ Type of prosthesis } & Role \\
\hline Internal & Articular: & \\
& Hip prosthesis & Functional \\
& Shoulder prosthesis & Functional \\
& Knee prosthesis & Functional \\
& Elbow prosthesis & Functional \\
& Hand joint prosthesis & Functional \\
\cline { 2 - 3 } & Cosmetic: & \\
& Dental prosthesis & Aesthetic and functional \\
& Breast prosthesis & Aesthetic \\
& Eye prosthesis & Aesthetic and functional \\
\hline External & Kidney dialysis system & Functional \\
& Artificial limbs & Functional \\
& Artificial hair & Aesthetic \\
& Artificial nose & Aesthetic and functional \\
\hline
\end{tabular}

Source: Pop, 2004

Many prosthetic parts are manufactured at present by casting or by conventional forming procedures (die forging, extrusion, stamping etc.), but these procedures require the often tedious, costly and time-consuming realising of individual moulds or dies, so the incremental forming option is much better suited for them.

On the other hand, for the manufacturing of prosthetic parts there are nowadays available a large variety of materials, so it can be a real challenge for professionals in this area (medical technicians but also physicians themselves) to determine which material is best suited for a certain prosthetic application, taking into account all important influencing factors.

Based on this problem, the current paper intends to present a new method, based on the calculation of a global suitability parameter, for selecting the best-suited material for the manufacturing, through incremental forming, of prosthetic parts for the usage in the human body. This parameter combines the influence of several properties of both the material and the manufacturing method and could be determined using data from a database with various material properties (which could be used flexibly for calculating 
suitability parameters also for other processing types or combinations of processes), leading to a clear result and even to a hierarchisation of materials that could be used for this purpose.

\section{Main influencing parameters in the manufacturing of prosthetic parts by incremental forming}

The concept of sheet metal forming comprises a large family of different forming operations, ranging from simple bending to stamping and deep drawing of complex shapes. The type of stresses and strains in each case varies accordingly and therefore the influencing parameters have to be analysed separately for each processing type.

Incremental forming can be regarded as a succession of local stretching and shallow drawing operations, so in the following there will be analysed only the formability parameters pertaining to this forming type.

A material with an optimal formability would display following characteristics (ASM International, 1996; Kalpakjan and Schmid, 2003):

- Uniform distribution of strains;

- Capability to reach high strain levels without necking or fracturing;

- Capability to withstand in-plane compressive stresses without wrinkling;

- Capability to withstand in-plane shear stresses without fracturing;

- Preservation of the shape after removal from the die;

- Capability to retain a smooth surface and resist surface damage;

The strain distribution in a forming operation, for example, is determined by three main parameters (ASM International, 1996):

- The strain-hardening coefficient, $n$;

- The strain rate sensitivity, $m$;

- The plastic strain ratio (anisotropy factor), $r$.

An even distribution of strains depends on the $n$ value and the $m$ value, while the ability to reach high overall strain levels depends on multiple factors, such as the material, $\mathrm{n}$ value, $\mathrm{m}$ value, $\mathrm{r}$ value, thickness, uniformity, and freedom from defects and inclusions (ASM International, 1996).

The strain-hardening coefficient, $n$, is determined by the dependence of the yield stress on the level of strain. In materials with a high $n$ value, the flow stress increases rapidly with strain. This tends to distribute further strain to regions of lower strain and flow stress. A high $\mathrm{n}$ value is also an indication of good formability in a stretching operation (ASM International, 1996; Callister, 2005).

For the case of uniform elongation and for most materials, the strain-hardening coefficient can be determined with the formula 1 (ASM International, 1996):

$\sigma_{T}=k \varepsilon^{n}$

where: $\sigma_{\mathrm{T}}$ is the true stress applied.

$\mathrm{k}$ is the strength coefficient, a material constant.

$\varepsilon_{\mathrm{n}}$ is the normal elongation.

A few materials, such as dual-phase steels or aluminum alloys, require the calculation of several $n$ values for low, intermediate, and high strain regions.

A more precise expression for equation 1 can be obtained by introducing as a supplemental, refining factor the strain rate sensitivity, $\mathrm{m}$, so the new formula is the one given in equation 2 (ASM International, 1996):

$\sigma_{T}=k \varepsilon^{n} \dot{\varepsilon}^{m}$

where $\varepsilon$ is the strain rate, $\mathrm{d} \varepsilon / \mathrm{dt}$.

When the strain rate sensitivity is positive, the flow stress increases with the rate of deformation. Therefore, at higher strain rates, higher stresses are required to form parts and at a given forming rate, the material resists further deformation in regions that are being strained more rapidly than adjacent regions by increasing the flow stress in these regions, so the strain is distributed more uniformly.(ASM International, 1996)

The plastic strain ratio or anisotropy factor, $r$, shows the capability of a material to resist thinning and can be defined as ratio of the true width strain $\varepsilon_{\mathrm{w}}$ to the true thickness strain $\varepsilon_{\mathrm{t}}$ (ASM International, 1996):

$$
r=\frac{\varepsilon_{w}}{\varepsilon_{t}}
$$


A high plastic strain ratio indicates a material with good drawing properties. Because $r$ can take different values function of the direction in the sheet, usually there is used an average value, called average normal anisotropy, $\mathrm{r}_{\mathrm{m}}$ (ASM International, 1996):

$$
(\mathrm{r} 0+2 \mathrm{r} 45+\mathrm{r} 90) / 4
$$

where the subscripts refer to the angle between the tensile specimen axis and the rolling direction.

Hot-rolled low-carbon steels have rm values ranging from 0.8 to 1.0; cold-rolled rimmed steels range from 1.0 to 1.4, and cold rolled aluminum-killed (deoxidized) steels range from 1.4 to 2.0. Interstitialfree steels have values ranging from 1.8 to 2.5 , and aluminum alloys range from 0.6 to 0.8 . (ASM International, 1996).

Since the prosthetic devices will be used in direct contact with the human body, one of the most important properties of a material employed for the manufacturing of such devices has to be, beneath the above-mentioned formability, their biocompatibility. This notion refers to the toleration of the metal by the human body and by the lack of toxic effects induced by it. Ideally, a metal used in or on the human body should not be damaging for the neighbouring tissues - skin, muscles, bones. Also, it should not contain toxic components that could be absorbed into the circulatory system and create so adverse systemic responses.

One of the parameters that is used in the speciality literature to quantify biocompatibility is the ABE potential (Anodic Back Electromotive Potential). It characterises the resistance to electrochemical corrosion in the specific conditions of living tissues and their environments. Table 2 (Deac et al., 1995) presents the values of this parameter for various metals, determined in sanguine serum at a temperature of $37^{\circ} \mathrm{C}$. A value of $300 \mathrm{mV}$ is generally accepted as the lower limit for the biocompatibility.

ABE potential of some metallic materials

\begin{tabular}{|c|c|c|c|}
\hline Material & $\begin{array}{c}\text { ABE Potential } \\
(\mathrm{mV})\end{array}$ & Material & $\begin{array}{c}\text { ABE Potential } \\
(\mathrm{mV})\end{array}$ \\
\hline $\mathrm{Ti}$ & +3500 & $\mathrm{Zr}$ & +320 \\
$\mathrm{nyy}$ & +1850 & $\mathrm{Ni}$ & +200 \\
$\mathrm{Nb}$ & +1650 & Stainless steel & +75 \\
$\mathrm{Ta}$ & +1450 & $\mathrm{Cu}$ & -30 \\
$\mathrm{Pt}$ & +1350 & $\mathrm{Co}$ & -350 \\
$\mathrm{Pd}$ & +1150 & Unalloyed steel & -480 \\
$\mathrm{Rh}$ & +1150 & $\mathrm{Fe}$ & -500 \\
$\mathrm{Ir}$ & +1000 & $\mathrm{Zn}$ & -1150 \\
$\mathrm{Au}$ & +750 & & \\
$\mathrm{Cr}$ & &
\end{tabular}

Source: Deac et al., 1995

It can be seen from this table that, while titanium and the noble metals, for example, easily surpass the biocompatibility limit, many other commonly used metals, like nickel, copper and iron are, in pure state, rather unsuitable for prosthetic devices.

Density is another important property for prosthetic parts, because lighter materials allow the realising of larger dental bridges, for example, without having their weight affecting the patient too much.

The higher the hardness of the prosthetic material is, the better their wear resistance will be. However, the increase of the hardness value must not come at the expense of the mechanical strength.

Not least, an important factor needs to be also the material's price - a cheaper material should be always chosen over a more expensive one with similar formability, mechanical or biocompatibility properties.

\section{Proposal for a new combined assessment parameter}

Based on the analysis presented in the previous paragraphs, a combined assessment parameter for materials that would be used in prostheses obtained by incremental forming (CAPifp), has to take into account the dominant factors influencing formability, but also others like biocompatibility, density and hardness.

Having taken into account all these elements, the authors of the current paper propose following formula for the proposed parameter CAPp:

$$
\mathrm{CAP}_{\mathrm{ifp}}=\frac{\sqrt{(\mathrm{ABE}-300)} \cdot \mathrm{R}_{\mathrm{p} 0.2} \cdot \mathrm{r} \cdot \mathrm{n}}{\rho \cdot \mathrm{H} \cdot \mathrm{p}},
$$

where: $R_{\mathrm{p} 0.2}=$ yield strength $\left(\mathrm{N} / \mathrm{mm}^{2}\right)$ 
$\mathrm{ABE}=\mathrm{ABE}$ potential, as measure for the biocompatibility, $(\mathrm{mV})$

$\mathrm{r}=$ the material's plastic strain ratio

$\mathrm{n}=$ the material's strain hardening coefficient

$\rho=$ the material's $\left(\mathrm{kg} / \mathrm{m}^{3}\right)$

$\mathrm{H}=$ the material's Vickers hardness $\left(\mathrm{N} / \mathrm{mm}^{2}\right)$

$\mathrm{p}=$ price factor (base metal alloys $-\mathrm{p} \approx 1$, high alloy materials $\mathrm{p} \approx 6$ )

The higher this parameter's value, the better the material's suitability for the intended usage should be. This formula takes into account the primary importance of the biocompatibility for prosthetic materials. If the value of ABE-300 is negative or zero, the materials should not be used for the manufacturing of prosthetic parts.

In order to test the efficiency of the new parameter, the authors have chosen several metallic materials whose main properties of interest have been previously determined and discussed in the speciality literature.

The materials are:

- $\quad$ stainless steel X12CrNi18-8

- titanium grade 2 (commercially pure titanium)

- Ti6A14V

- aluminum alloy 7075

The main properties of these materials are given in table 3 .

Table 3 Main properties of the analysed metallic materials

\begin{tabular}{|c|c|c|c|c|}
\hline Property & $\begin{array}{l}\text { Stainless steel } \\
\text { X12CrNi18-8 }\end{array}$ & $\begin{array}{l}\text { Aluminum alloy } \\
7075\end{array}$ & Titanium grade 2 & Ti6Al4V \\
\hline \begin{tabular}{|l|} 
Chemical \\
composition
\end{tabular} & $\begin{array}{c}18 \% \mathrm{Cr}, 8 \% \mathrm{Ni}, \\
2 \% \mathrm{Mn} \\
0.03 \% \mathrm{C}^{1}\end{array}$ & $\begin{array}{c}5.8 \% \mathrm{Zn}, 2.5 \% \mathrm{Mg} \\
1.6 \% \mathrm{Cu}, 0.28 \% \\
\mathrm{Mn}, 0.40 \% \mathrm{Fe} \\
0.35 \% \mathrm{Si}, 0.21 \% \\
\mathrm{Cr}, \text { rest } \mathrm{Al}^{3}\end{array}$ & $\begin{array}{c}99.2 \% \mathrm{Ti} \\
<0.1 \% \mathrm{C} \\
<0.03 \% \mathrm{Fe} \\
<0.025 \% \mathrm{O}^{1,4}\end{array}$ & $\begin{array}{c}6.1 \% \mathrm{Al}, 4.3 \% \mathrm{~V} \\
0.16 \% \mathrm{Fe}, 0.01 \% \mathrm{C} \\
\operatorname{rest~Ti~}^{6}\end{array}$ \\
\hline $\begin{array}{l}\text { Yield strength } \\
\mathrm{R}_{\mathrm{p} 0.2}[\mathrm{MPa}]\end{array}$ & $210^{1}$ & $96.5-138^{1}$ & $340^{1,4}$ & $560^{6}$ \\
\hline Density $\rho\left(\mathrm{kg} / \mathrm{m}^{3}\right)$ & $8000^{1}$ & $2810^{1}$ & $4510^{1}$ & $4430^{1}$ \\
\hline Vickers hardness HV & $159^{1}$ & $175^{1}$ & $145^{1}$ & $349^{1}$ \\
\hline Plastic strain ratio $r$ & $1,04^{5}$ & $0.79^{3}$ & $4.41^{1}$ & $3.21^{4}$ \\
\hline $\begin{array}{l}\text { Strain hardening } \\
\text { coefficient } n\end{array}$ & $0.23^{5}$ & $0.14^{3}$ & $0.08^{1}$ & $0.15^{4}$ \\
\hline
\end{tabular}

Sources: ${ }^{1}$ Matweb, $2013{ }^{2}$ Callister, $2005{ }^{3}$ Tajally, $201{ }^{4}$ Djavanroodi and Janbakhsh, $2013{ }^{5}$ Bhatt and Bhatt, 2012

The first remark has to be that, while stainless steel has better formability properties than, for example aluminum, its biocompatibility is very low, so, unless it is coated with some biocompatible alloy, it has to be dropped as material for prosthetics.

After substituting these values in equation 5, it can be seen that overall, the alloy Ti6Al4V is better suited for the intended application than the aluminum alloy or commercially pure titanium grade 2 .

\section{Conclusions}

The present paper has shown some efforts by the authors on the one hand to find a theoretical way for detecting materials, and especially biocompatible metallic materials, that can be used for the manufacturing, through incremental forming, of parts for prosthetic devices used in or on the human body and on the other hand, to implement the determined CAPifp parameter in such manner that a quick and easy determination of this parameter and a reliable relative comparison of the available materials based on the combined assessment parameter becomes possible.

Furthermore, it has been shown that, while the structure of the parameter itself is not a very complicated one, it allows a hierarchisation of the suitable material solutions, but at the same time it helps eliminating from the start the materials that are not suitable, especially from the point of view of biocompatibility. If the device consists of parts made of several different materials, a manufacturer could choose the materials so that they are matching with regard to either all or just certain properties, or, to the 
contrary, it would allow to choose a material whose properties would complement those of another material that has already been selected.

The best way to determine this parameter would be by linking the formula to an object-relational database containing the material's general characterics, its physical-chemical properties and the mechanical properties.

Such a system for the selection of suitable materials can access material data stored in the database files (material name, manufacturing company, material type, chemical composition, melting range, yield strength etc.) or allows also the manual introduction of parameters, especially of parameters depending on direct experimental results. It can then order the CAPifp value of the various materials (or the values of other similar suitability parameters, if there is a possibility to realise a part through different manufacturing procedures). Furthermore, starting from a given material, it allows also to identify materials with similar values of the $\mathrm{CAP}_{\text {ifp }}$ and could rank them function of one specific parameter.

This paper has treated formability strictly from the point of view of the material's intrinsec properties, but for the future, the CAP ${ }_{\text {ifp }}$ parameter could be refined by taking into account also other parameters and different part conditions/treatments. The current approach requires, for example, a hardened steel and a normalised steel to be treated separately within the database and for the calculation of the $\mathrm{CAP}_{\text {ifp. }}$. Therefore, it is sought to follow the current attempts at matematical modelling of the properties' variations under various conditions and to introduce the results in the $\mathrm{CAP}_{\text {ifp }}$ 's calculation procedure.

\section{References}

- ASM International, (1996), ASM Handbook, Vol. 14 - Forming and Forging.

- Bhatt R. and Bhatt M. (2012), FLD Creation for SS304 Using Experiments \& It's Validation Using HyperForm 11.0, HTC 2012, http://www.altairatc.com/india/previous-years/htc2012/papers2012/MFG_04_FLD_Creation_for_SS304_Using_Experiments_NirmaUniversity.pdf

- Blaga A., (2011), Contribuții la deformarea incrementală a tablelor metalice subțiri, doctoral thesis, Universitatea "Lucian Blaga" din Sibiu.

- Bruschi S., Poggio S., Quadrini F., Tata E. (2004), Workability of Ti6Al4V alloy at high temperature and strain rate, Materials Letters, vol. 58, no. 27-28, p. 3622-3629

- Callister, Jr., W.D. (2005), Fundamentals of Materials Science and Engineering (2nd ed.), United States of America: John Wiley \& Sons, p. 199

- Deac V et al., (1995), The casting of titanium in dental prosthetics (in Romanian), Publishing House of the University of Sibiu.

- Djavanroodi F., Janbakhsh M., Formability Characterization of Titanium Alloy Sheets, in Titanium Alloys - Advances in Properties Control, Edited by Jan Sieniawski and Waldemar Ziaja, Intech, 2013- p. 81-114

- Gottmann A. et al., (2011), Laser-assisted asymmetric incremental sheet forming of titanium sheet metal parts, Prod. Eng. Res. Devel., 5:263-271.

- Kalpakjian S., Schmid S.R. (2003), Manufacturing Processes for Engineering Materials. 4th Ed., Prentice Hall.

- Matweb - Material Property Data (2013), http://www.matweb.com

- Pop Gh., (2004), Biomateriale şi componente protetice metalice, Ed.Tehnopress, Iaşi, 2004.

- Tajally M., Emadoddin E. (2011), Mechanical and anisotropic behaviors of 7075 aluminum alloy sheets, Materials \& Design, Vol. 32, no. 3, March 2011, p. 1594-1599 